
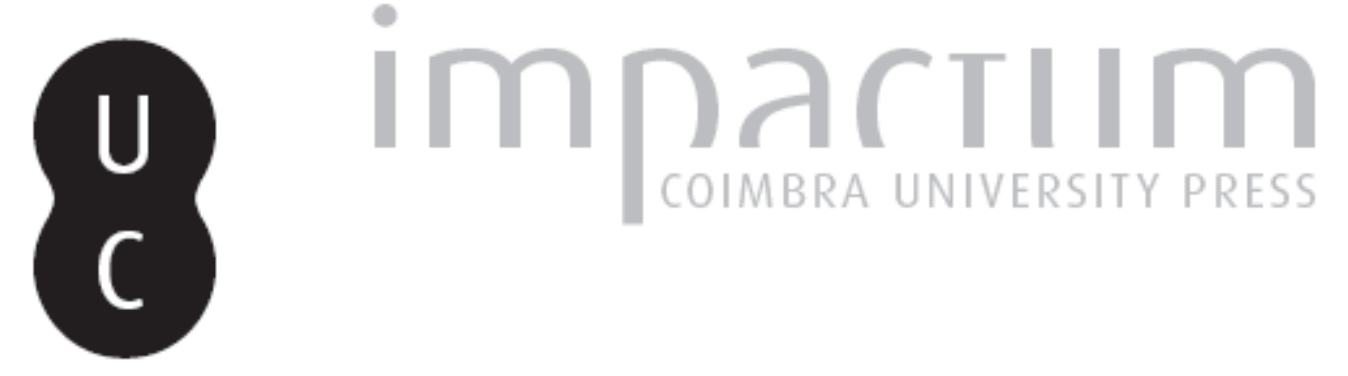

\title{
Avaliação do risco de incêndio dum edifício de triagem de resíduos sólidos urbanos: comparação entre a aplicação do método de Gretener e o Frame
}

Autor(es): $\quad$ Barra, Cecília P.; Rodrigues, João P.; Fitzgerald, Robert W.

Publicado por: $\quad$ Associação Portuguesa de Riscos, Prevenção e Segurança

URL

persistente:

URI:http://hdl.handle.net/10316.2/35126

DOI:

DOI:http://dx.doi.org/10.14195/1647-7723_21_12

Accessed : $\quad$ 26-Apr-2023 13:31:36

A navegação consulta e descarregamento dos títulos inseridos nas Bibliotecas Digitais UC Digitalis, UC Pombalina e UC Impactum, pressupõem a aceitação plena e sem reservas dos Termos e Condições de Uso destas Bibliotecas Digitais, disponíveis em https://digitalis.uc.pt/pt-pt/termos.

Conforme exposto nos referidos Termos e Condições de Uso, o descarregamento de títulos de acesso restrito requer uma licença válida de autorização devendo o utilizador aceder ao(s) documento(s) a partir de um endereço de IP da instituição detentora da supramencionada licença.

Ao utilizador é apenas permitido o descarregamento para uso pessoal, pelo que o emprego do(s) título(s) descarregado(s) para outro fim, designadamente comercial, carece de autorização do respetivo autor ou editor da obra.

Na medida em que todas as obras da UC Digitalis se encontram protegidas pelo Código do Direito de Autor e Direitos Conexos e demais legislação aplicável, toda a cópia, parcial ou total, deste documento, nos casos em que é legalmente admitida, deverá conter ou fazer-se acompanhar por este aviso.

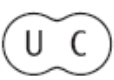




\section{territorium}

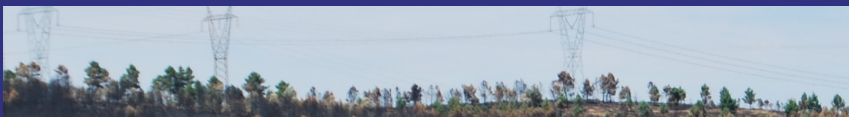

y

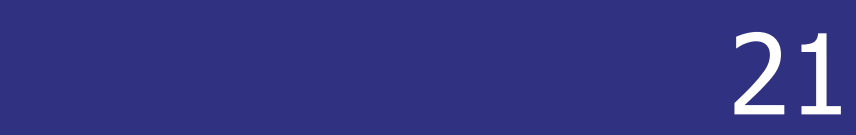

Territórios de risco: processos, vulnerabilidades e segurança

Revista da Associação Portuguesa de Riscos, Prevenção e Segurança 


\section{AVALIAÇÃO DO RISCO DE INCÊNDIO DUM EDIFÍCIO DE TRIAGEM DE RESÍDUOS SÓLIDOS URBANOS. COMPARAÇÃO ENTRE A APLICAÇÃO DO MÉTODO DE GRETENER E O FRAME*}

Cecília P. Barra

Doutoranda em Engenharia de Segurança ao Incêndio UC, Portugal cmpbarra@gmail.com

João P. Rodrigues

Professor na Universidade de Coimbra, Portugal jpaulocr@dec.uc.pt

Robert W. Fitzgerald

Professor at the Worcester Polytechnic Institute, USA rfitz@wpi.edu

\section{RESUMO}

A partir dos métodos de Gretener e do FRAME, para a avaliação do risco de incêndio, efetuou-se uma análise desensibilidade para determinar quais os parâmetros destes métodos que têm maior influência na segurança contraincêndio dum edifício industrial, destinado à triagem de resíduos sólidos urbanos provenientes dos concelhos de Olhão,Faro e Loulé. A fiabilidade do sistema de abastecimento de água no método de Gretener e a rápida intervenção dos bombeiros noFRAME foram os parâmetros que mostraram ter mais influência.

Palavras-chave: Incêndio, indústria, risco, sensibilidade, método.

\section{RESUMEN}

Evaluación de riesgo de incendio en una instalación de separación de residuos sólidos urbanos comparación entre laaplicación del método de Gretener e FRAME - A partir de lo método de Gretener y de lo FRAME, para evaluaciónde riesgo de incendio, se realizó un análisis de sensibilidad para determinar cuáles son los parámetros de estos métodosque tienen mayor influencia en la seguridad contra incendios de un edificio destinado a separación y clasificación deresiduos sólidos municipales de los municipios de Olhão, Faro y Loulé. La fiabilidad del sistema de abastecimiento deagua en el método de Gretener y la rápida intervención de los bomberos en el FRAME fueron los parámetros que mostraran tener mais influencia.

Palabras clave: Incêndio, indústria, riesgo, sensibilidad, método.

\section{RÉSUMÉ}

Évaluation du risque incendie d'une installation de séparation de déchets solides municipaux - comparaison entrel'application d'el méthode de Gretener et el FRAME - Prenant en considération el méthode de Gretener et el FRAME, pour l'évaluation du risque de incendie, se a effectué une analyse de sensibilité pour déterminer ce que les paramètresde ces méthodes ayant plus influence en la sécurité contre incendie d'un immeuble industriel, de séparation et classificationde déchets solides municipaux des municipalités de Olhão, Faro et Loulé. La fiabilité du système d'approvisionnementde eau dans le metode de Gretener et l'intervention rapide des pompiers en el FRAME sont les paramètres qui ont montré plus d'influence.

Mots-clé: Incendie, industrie, risque, sensibilité, méthode.

\section{ABSTRACT}

Fire risk assessment of an installation of separation and classification of municipal solid waste - comparison betweenthe application of the method of Gretener and FRAME - Taking into account the Gretener method and the FRAMEfor fire risk assessment, a sensitivity analysis was carried out to know which parameters of these methods havemore influence on the fire safety of a building dedicated to the separation and classification of municipal solid wastefrom the municipalities of Olhão, Faro and Loulé. The reliability of the water supply system in the Gretener method and rapidintervention of the firemen in the FRAME were the parameters that showed more influence.

Keywords: Fire, industry, risk, sensitivity, method.

* O texto deste artigo foi submetido em 25-12-2013, sujeito a revisão por pares a 18-02-2014 e aceite para publicação em 07-05-2014. Este artigo é parte integrante da Revista Territorium, n. ${ }^{\circ} 21,2014,{ }^{\circ}$ RIscos, ISBN: $0872-8941$. 


\section{Introdução}

O risco de incêndio nos edifícios industriais é bastante complexo não só pela diversidade das suas instalações mas também pelos perigos que cada uma compreende.

A existência de um incêndio neste tipo de instalação pode originar perdas de vidas humanas, de bens materiais e paragens na produção, com os consequentes problemas económicos, pelo que, é de todo o interesse o estudo do risco de incêndio em industrias com vista à redução e limitação de perdas, de forma a permitir que a evacuação dos ocupantes se faça de uma forma rápida e segura e a intervenção dos bombeiros seja facilitada e efectuada em segurança, (BARRA, 2010).

A entrada em vigor do Decreto-Lei $n^{\circ} 220 / 08$ de 12 de Novembro que estabelece o regime jurídico da segurança contra incêndios em edifícios, e da Portaria $n^{\circ} 1532 / 08$ de 29 de Dezembro, que define o regulamento técnico de segurança contra incêndio em edifícios, trouxe com a Utilização-Tipo XII a figura dos edifícios industriais, que até então não havia ainda sido tratada mostrando assim a preocupação com este tipo de utilização.

Dos diversos métodos de avaliação do risco de incêndio em edifícios industriais escolheram-se dois, o método de Gretener e o FRAME e com eles pretende-se efetuar uma análise de sensibilidade para determinar os parâmetros que maior influência exercem no aumento da segurança contra incêndio deste tipo de edifícios industriais.

\section{Metodologia}

\section{Método de Gretener}

O método de Gretener é um método de natureza empírica que foi criado pelo engenheiro Max Gretener na década de 60 , na Suíça, com o objetivo de quantificar o risco de incêndio fundamentalmente em edifícios industriais (Neves et al., 2004).

O grande potencial deste método deriva da sua simplicidade matemática e da riquezadas suas tabelas, desenvolvidas com fundamentação estatística.

Permite avaliar e comparar o nível do risco de incêndio de diferentes hipóteses graduando elementos da edificação e seus desempenhos, ordenando, combinando e acumulando alternativas aplicadas até à obtenção do nível de segurança desejado.

Este método avalia o risco de incêndio dos edifícios industriais e dos edifícios de grandes dimensões e parte do princípio que são observadas as regras gerais de segurança, tais como distâncias de segurança entre edifícios vizinhos e sobretudo as medidas de proteção das pessoas como saídas de evacuação, iluminação de segurança, etc., bem como as prescrições correspondentes às instalações técnicas.
O estudo do risco de incêndio desenvolve-se em duas etapas fundamentais.

A primeira etapa determina o perigo potencial $P$, que envolve os perigos inerentes ao conteúdo do edifício (fator carga de incêndio mobiliária, combustibilidade, produção de fumo e perigo de corrosão/toxicidade) e os perigos inerentes ao edifício (carga de incêndio imobiliária, nível do andar e dimensão do próprio compartimento de incêndio.

0 produto destes sete fatores determina o perigo potencial $P$.

A segunda etapa vai determinar as medidas contra o desenvolvimento do incêndio que corresponde ao produto entre as medidas de proteção normal $\mathrm{N}$, as medidas especiais de proteção $\mathrm{S}$ e as medidas de proteção da construção F.

Nas medidas de proteção normal inclui-se informação relativa aos extintores, bocas-de-incêndio armadas, fiabilidade do abastecimento de água,

As medidas especiais de proteção incluem informação sobre a deteção do incêndio, transmissão do alerta, o tipo de intervenção por bombeiros profissionais ou brigadas privadas, o tempo de intervenção desses bombeiros ou dessas brigadas, sistemas de extinção e de evacuação automática de calor e fumo.

As medidas de proteção da construção contêm informação sobre o tipo de resistência ao fogo dos diversos componentes do edifício nomeadamente da estrutura resistente, das fachadas, dos pavimentos e da superfície das células corta-fogo.

Donde se obtém o fator de exposição ao fogo $B$, que resulta do quociente entre o perigo potencial $P$ e o produto entre as medidas de proteção N, S e F.

O perigo de ativação A vai quantificar a probabilidade de ocorrência de um incêndio avaliando assim as fontes de ignição cuja energia calorífica ou de ignição é suscetivel de desencadear um processo de combustão.

O perigo de ativação depende de fatores humanos e de fatores ligados à exploração.

Entre os fatores humanos há os relacionados com a desordem, manutenção, disciplina quanto à utilização de chamas vivas, fumadores, etc., nos fatores relacionados com a exploração tem-se os de natureza térmica, elétrica, mecânica e química.

$O$ risco de incêndio efetivo $R$ resulta do produto entre o fator de exposição ao fogo B pelo perigo de ativação $A$.

$O$ risco de incêndio admissível $R_{u}$ deve ser definido em cada caso e para cada edifício.

O método de Gretener recomenda fixar o valor limite admissível partindo de um risco normal $R_{n}$, fixado em 
1,3 e introduzindo um fator de correção $P_{H E}$ que tem em conta um maior ou menor perigo para as pessoas.

$O$ nível de segurança ao incêndio $\gamma$ do edifício é determinado através do quociente entre o risco admissível Ru e o risco efetivo $\mathrm{R}$, donde resulta que se $\gamma<1$ o edifício é inseguro e se $\gamma \geq 1$ o edifício é seguro.

Sendo o edifício inseguro é então necessário reformular os conceitos de proteção do mesmo e para isso iniciase o processo através do melhoramento das medidas de proteção normais porque são as que apresentam custos mais baixos na sua implementação, seguidas da implementação das medidas de proteção especiais que são bem mais eficazes mas com custos bastante mais elevados e por último, se as anteriores medidas ainda não forem suficientes para tornar o edifício seguro, é que se irá melhorar as medidas de proteção da construção.

\section{FRAME}

O método de FRAME, Fire Risk Assessment Method for Engineering, foi desenvolvido a partir do método de Gretener pelo engenheiro Belga Erik De SMET e pretende calcular o risco de incêndio nos edifícios através do cálculo do risco para os bens patrimoniais, para os ocupantes e para as atividades desenvolvidas no edifício (SMET, 2008).

Cada um destes riscos resulta do quociente entre o risco potencial $\mathrm{P}$ pelo produto entre o risco aceitável A pelo nível de proteção $D$, se o valor obtido for menor ou igual a 1 , considera-se que o risco de incêndio é aceitável.

Assim, tem-se para o edifício três tipos distintos de riscos, risco para os bens patrimoniais $R$, risco para os ocupantes $R_{1}$ e o risco para as atividades $R_{2}$.

Como este método deriva do método de Gretener contém os mesmos conceitos de aplicação e de efeitos mas apresenta os resultados de forma mais detalhada.

Os seus resultados são apresentados relativamente ao risco para valores inferiores à unidade, ou seja, para que um compartimento esteja protegido contra o incêndio os valores obtidos de $R, R_{1}$ e $R_{2}$ têm de ser menores ou iguais a 1 .

Para o cálculo do risco para os bens patrimoniais $R$, o risco potencial $P$ é influenciado pela carga calorífica e pelos fatores de propagação, de geometria horizontal, dos andares, de ventilação e de acessibilidade.

O risco aceitável A é afetado pelos fatores de ativação, de evacuação e de conteúdo.

$\mathrm{O}$ nível de proteção para os bens patrimoniais $\mathrm{D}$ abrange o fator de recursos de água W (tipo de reserva de água, capacidade do depósito, rede de distribuição, pressão na rede, hidrantes) o fator de proteção normal $N$ (que inclui o sistema de alarme, os meios de $1^{\text {a }}$ intervenção, intervenção dos bombeiros e formação) o fator de proteção especial $\mathrm{S}$ (deteção automática, reservas de água, proteção automática do compartimento e corpo de bombeiros) e o fator de resistência ao fogo $F$ (dos elementos estruturais, das fachadas, dos tetos e das paredes interiores).

No cálculo do risco para os ocupantes $R_{1}$, o risco potencial para os ocupantes $P_{1}$ é afetado dos fatores de carga calorífica, de propagação, de andares, de ventilação e de acessibilidade.

O risco aceitável para os ocupantes $\mathrm{A}_{1}$ envolve os fatores de ativação, de evacuação e de ambiente.

$O$ nível de proteção para os ocupantes $D_{1}$ compreende o fator de proteção normal $\mathrm{N}$ e o fator de fuga $U$ (que inclui a deteção automática, os meios de evacuação, a compartimentação, a proteção e as brigadas de incêndio).

E finalmente no cálculo do risco para as atividades $R_{2}$ temos que o risco potencial para as atividades $\mathrm{P}_{2}$ é afetado dos fatores de propagação, de geometria horizontal, dos andares, de ventilação e de acessibilidade.

$O$ nível de proteção para as atividades $D_{2}$ envolve os fatores dos recursos de água $\mathrm{W}$, de proteção normal $\mathrm{N}$, de proteção especial $\mathrm{S}$ e de salvaguarda $Y$ (que inclui a proteção física e a organização).

Se os valores calculados para os riscos dos bens patrimoniais, dos ocupantes e das atividades $R, R_{1}$ e $R_{2}$ respetivamente forem menores ou iguais a 1 , o edifício ou compartimento encontra-se protegido contra um incêndio.

Antes de se iniciar o cálculo para a determinação dos diversos riscos $R, R_{1}$ e $R_{2}$ é conveniente efetuar o cálculo do risco inicial $R_{0}$.

O risco inicial $\mathrm{R}_{0}$ é o ponto de partida para na elaboração do projeto de arquitetura prever as medidas de segurança e proteção a implementar.

\section{Análise de sensibilidade}

Através de uma análise de sensibilidade efetuada nos métodos de Gretener e FRAME procurou determinar-se qual ou quais os parâmetros de ambos os métodos que maior influência têm na proteção e segurança contra incêndio de um edifício industrial.

Neste edifício, situado no concelho de Faro, efetua-se a triagem dos resíduos sólidos urbanos provenientes dos ecopontos existentes nos concelhos de Olhão, Faro e Loulé, (fig.1).

É um edifício de um só piso com uma área de 1173,15 m² e cerca de $11 \mathrm{~m}$ de altura, (fig.2).

No seu interior são depositados e enfardados o resultante da triagem, (fig. 3 e 4).

No exterior, na envolvente ao edifício, são depositados separadamente, vidros, vasos de plástico, pneus, colchões, etc., (fig.5). 


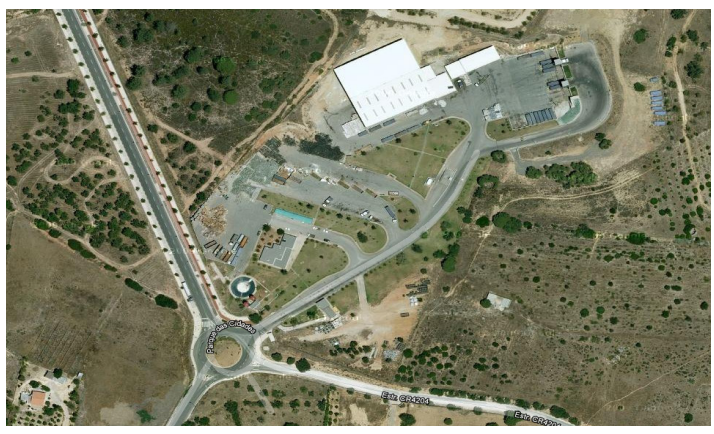

Fig. 1 - Edifício industrial. Fonte: Google Maps.

\section{Parâmetros adotados para o método de Gretener}

$\mathrm{Na}$ análise de sensibilidade efetuada ao método de Gretener começou-se por fixar os valores mais baixos das medidas de proteção especiais $S$ e de proteção da estrutura F, QUADRo I e II, , e os valores das medidas de proteção normais $\mathrm{N}$, foram variando ao longo de 14 combinações, Quadro III.

Tomou-se para a carga de incêndio mobiliária $\mathrm{Q}_{\mathrm{m}}=500 \mathrm{MJ} / \mathrm{m}^{2}$, locais de resíduos diversos valor retirado do Anexo 1 (Neves et al., 2004).

Os valores de $\mathrm{n}_{1}, \mathrm{n}_{2}, \mathrm{n}_{3}, \mathrm{n}_{4}$ e $\mathrm{n}_{5}$ das medidas de proteção normais $N$, tomam os diversos valores indicados nas 14 combinações, de A1 a A14 enquanto os valores de S e F mantêm-se constantes ao longo das 14 combinações nos seus valores mais baixos.

A primeira combinação A1 corresponde à pior possibilidade de todas ou seja, é onde $n_{1}, n_{2}, n_{3}, n_{4}$ e $n_{5}$ têm os valores mais baixos possíveis.

Segue-se A2 onde $n_{1}=1,0$ o que significa que tem extintores portáteis suficientes.

Passando para A3 temos $n_{1}=0,9$ e $n_{2}=1,0$ que nos indica que não há extintores portáteis mas há bocas de incêndio armadas, os restantes nos seus valores mais baixos.

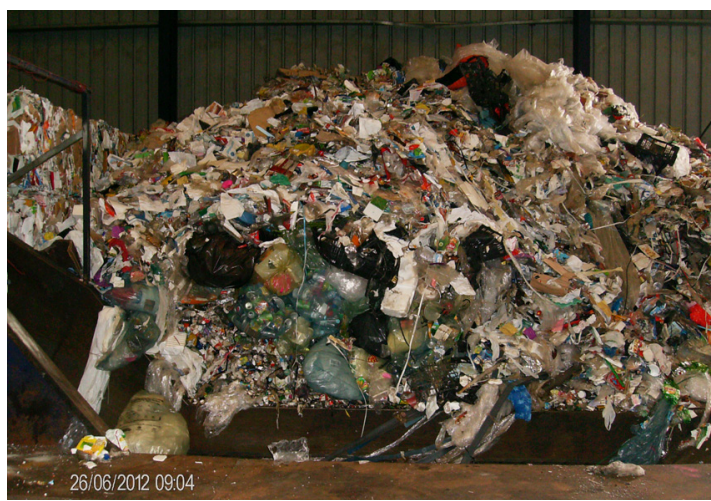

Fig. 3 - Interior do edifício, plásticos.

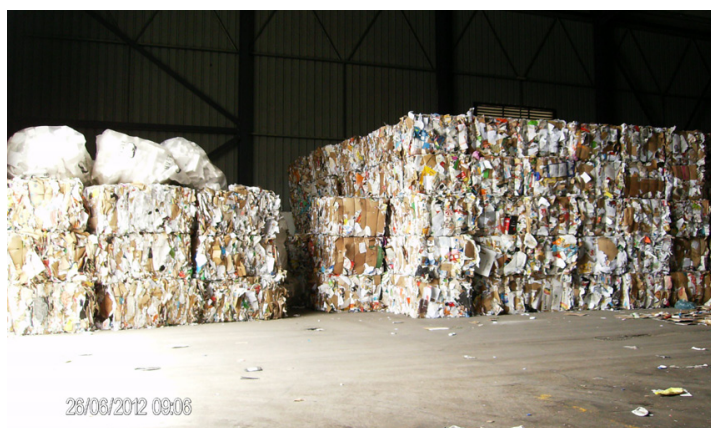

Fig. 4 - Interior do edifício, fardos de papel.

QuAdro I - Medidas Especiais S.

\begin{tabular}{|c|c|c|}
\hline $\mathrm{s}_{1}$ & 1,00 & sem deteção ao fogo \\
\hline $\mathrm{S}_{2}$ & 1,00 & $\begin{array}{l}\text { sem transmissão de alerta ao posto de } \\
\text { alerta de incêndio }\end{array}$ \\
\hline $\mathrm{s}_{3}$ & 1,00 & sem BE (Bombeiros de Empresa) \\
\hline $\mathrm{S}_{4}$ & 0,60 & $\begin{array}{l}\text { tempo de intervenção dos corpos de } \\
\text { bombeiros (>30 minutos) }\end{array}$ \\
\hline $\mathrm{S}_{5}$ & 1,00 & sem instalação de sprinklers \\
\hline $\mathrm{s}_{6}$ & 1,00 & $\begin{array}{l}\text { sem evacuação automática de calor e } \\
\text { de fumo (EACF) }\end{array}$ \\
\hline
\end{tabular}
Fonte: adaptado de NEVEs et al., 2004.

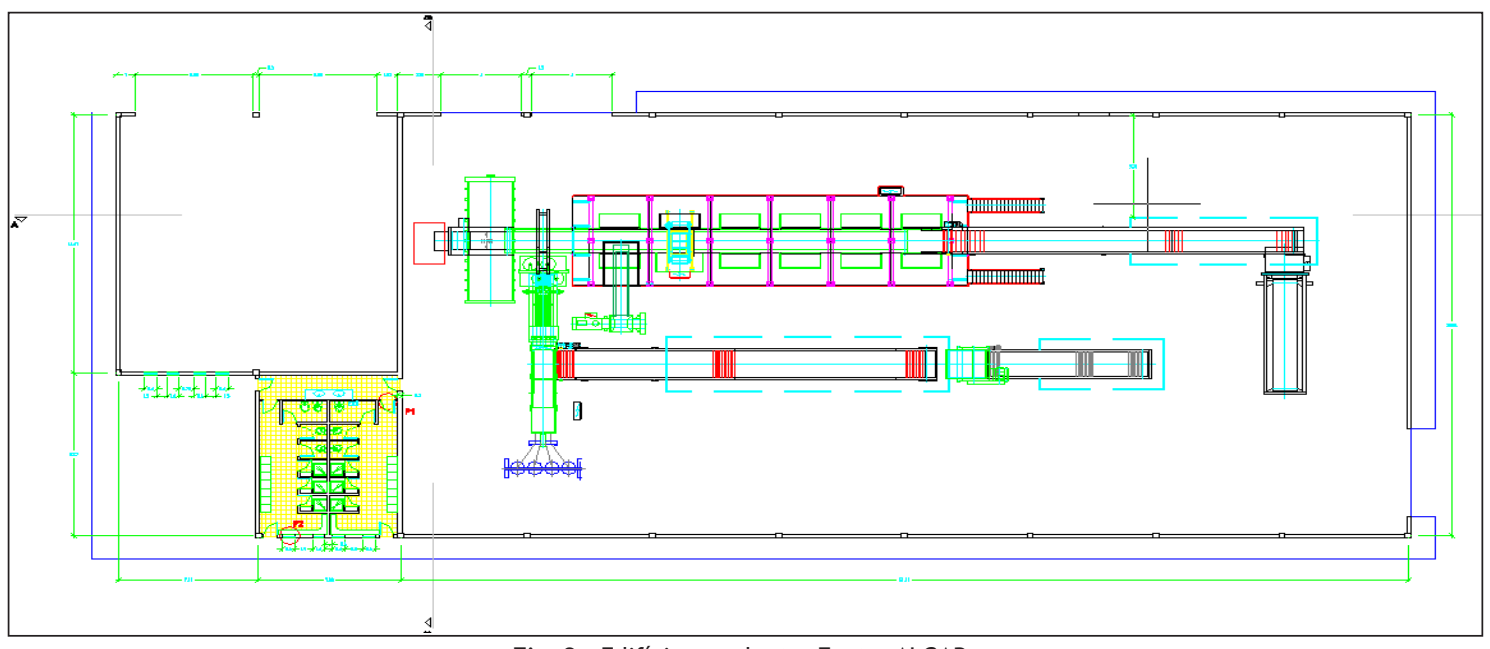

Fig. 2 - Edifício em planta. Fonte: ALGAR. 
QuAdro II - Medidas de Proteção da Estrutura F.

\begin{tabular}{|lll|}
\hline$f_{1}$ & 1,00 & estrutura resistente $<F 30$ \\
\hline$f_{2}$ & 1,00 & fachadas $<F 30$ \\
\hline$f_{3}$ & 1,00 & pavimentos $<F 30$ \\
\hline$f_{4}$ & 1,00 & superfície das células \\
\hline
\end{tabular}

Fonte: adaptado de Neves et al., 2004.
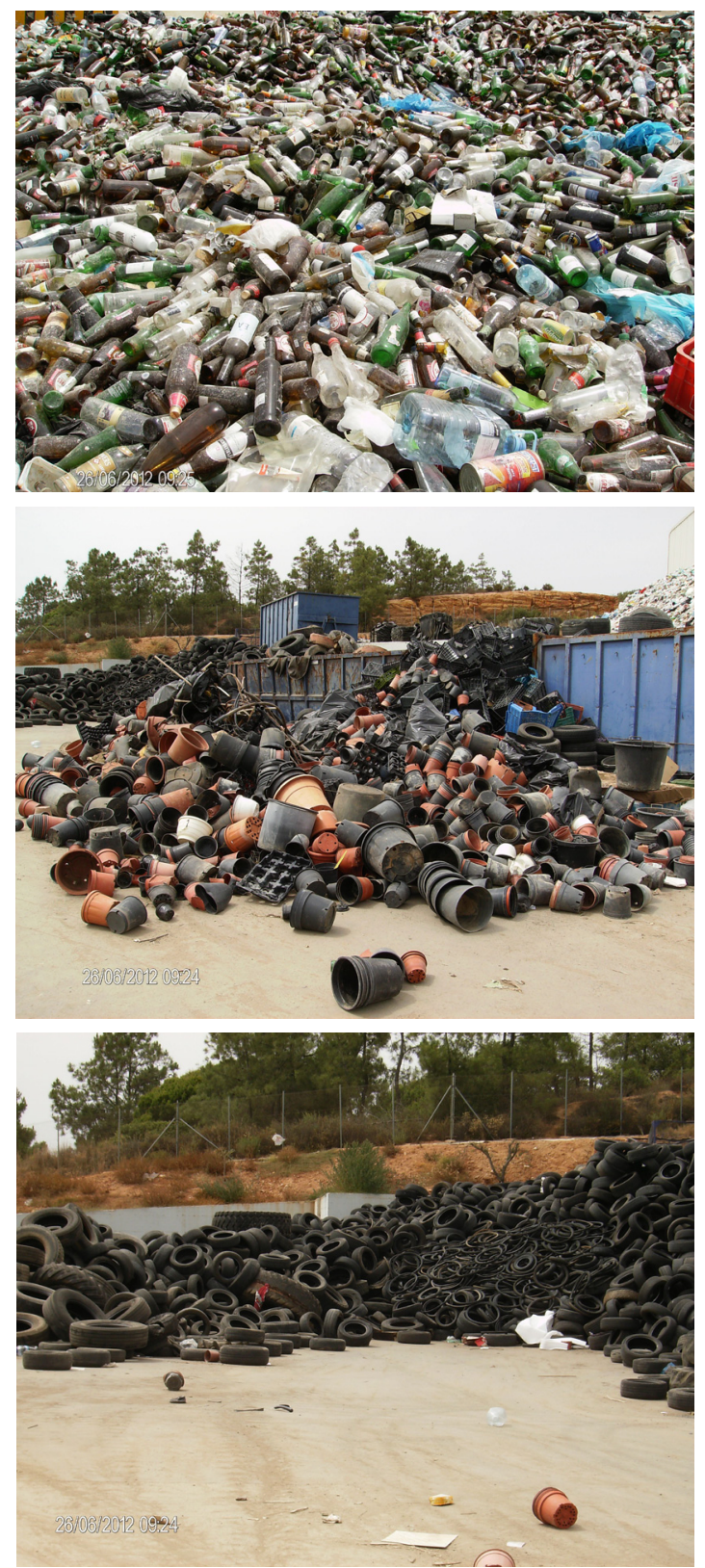

Fig. 5 - Exterior do edifício, garrafas de vidro, vasos de plástico e pneus.

As combinações de A4 a A11 tratam da variação existente na fiabilidade do sistema de abastecimento de água de 0,55 a 1,0. 0 valor mais baixo 0,50 estava incluído na combinação A1.

As combinações $\mathrm{A} 12$ e A13 averiguam os valores relativos ao comprimento da conduta desde o hidrante exterior até à porta do edifício enquanto a última combinação
A14, corresponde à influência que a formação dos trabalhadores tem face a um incêndio nomeadamente na utilização dos meios de $1^{\text {a }}$ intervenção.

Face ao descrito resultam então 14 combinações e através delas pode-se verificar a influência, maior ou menor, que cada um dos $n_{1}, n_{2}, n_{3}, n_{4}$ e $n_{5}$ exercem na segurança contra incêndio do edifício.

No QUADRo IV indica-se os resultados obtidos para a segurança ao incêndio em cada uma das combinações.

$\mathrm{Na}$ fig.6 indica-se a variação dos diversos valores atribuídos nas medidas de proteção normais ao longo das 14 combinações.

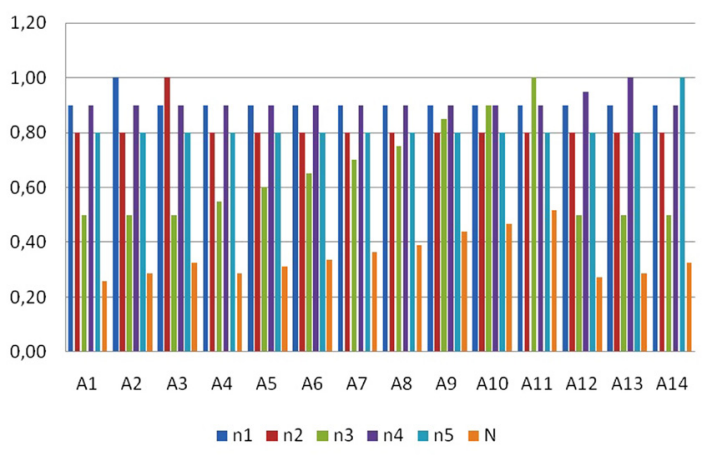

Fig. 6 - Variação dos valores nas Medidas de Proteção Normais N.

A fig.7 apresenta a variação das medidas de proteção normais $\mathrm{N}$, das medidas de proteção especiais $\mathrm{S}$ e de proteção da estrutura $F$ que são fixas, em função do resultado do nível de segurança ao incêndio SI (ou Y) nas 14 combinações.

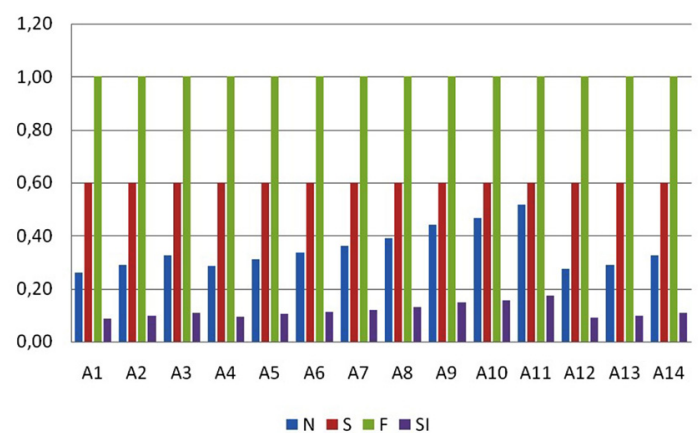

Fig. 7 - Variação das medidas N, S, F e SI.

Verifica-se que a combinação que permite obter o melhor resultado é a combinação A11, que corresponde ao melhor valor de $\mathrm{N}$ e consequentemente ao melhor valor obtido para a Segurança ao Incêndio SI do edifício/ compartimento de incêndio, (fig.7).

A esta combinação A11 corresponde:

- $\mathrm{n}_{1}=0,90$ - extintores portáteis insuficientes ou inexistentes;

- $\mathrm{n}_{2}=0,80$ - bocas-de-incêndio armadas insuficientes ou inexistentes; 
Quadro III - Medidas de Proteção Normais N.

\begin{tabular}{|c|c|c|c|c|c|}
\hline $\begin{array}{c}\text { C } \\
\text { Combinações }\end{array}$ & $\begin{array}{c}\mathrm{n}_{1} \\
\text { Extintores } \\
\text { portáteis }\end{array}$ & $\begin{array}{c}\mathrm{n}_{2} \\
\text { Bocas de incêndio } \\
\text { armadas }\end{array}$ & $\begin{array}{c}\mathrm{n}_{3} \\
\text { Fiabilidade do sistema de } \\
\text { abastecimento de água }\end{array}$ & $\begin{array}{c}\mathrm{n}_{4} \\
\text { Comprimento } \\
\text { da conduta }\end{array}$ & $\begin{array}{c}\mathrm{n}_{5} \\
\text { Pessoal } \\
\text { instruído }\end{array}$ \\
\hline A1 & 0,90 & 0,80 & 0,50 & 0,90 & 0,80 \\
\hline A2 & 1,00 & 0,80 & 0,50 & 0,90 & 0,80 \\
\hline A3 & 0,90 & 1,00 & 0,50 & 0,90 & 0,80 \\
\hline A4 & 0,90 & 0,80 & 0,55 & 0,90 & 0,80 \\
\hline A5 & 0,90 & 0,80 & 0,60 & 0,90 & 0,80 \\
\hline A6 & 0,90 & 0,80 & 0,65 & 0,90 & 0,80 \\
\hline A7 & 0,90 & 0,80 & 0,70 & 0,90 & 0,80 \\
\hline A8 & 0,90 & 0,80 & 0,75 & 0,90 & 0,80 \\
\hline A9 & 0,90 & 0,80 & 0,85 & 0,90 & 0,80 \\
\hline A10 & 0,90 & 0,80 & 0,90 & 0,90 & 0,80 \\
\hline A11 & 0,90 & 0,80 & 1,00 & 0,95 & 0,80 \\
\hline A12 & 0,90 & 0,80 & 0,50 & 1,00 & 0,80 \\
\hline A13 & 0,90 & 0,80 & 0,50 & 0,90 & 1,00 \\
\hline A14 & 0,90 & 0,80 & 0,50 & & 0 \\
\hline
\end{tabular}

C - Combinações; $n_{1}$ - Extintores portáteis; $n 2$ - Bocas de incêndio armadas; $n_{3}$ - Fiabilidade do sistema de abastecimento de água; $\mathrm{n} 4$ - Comprimento da conduta; $\mathrm{n}_{5}$ - Pessoal instruído.

- $\mathrm{n}_{3}=1,00$ - fiabilidade do sistema de abastecimento de água com reservatório elevado com reserva de água para incêndio ou bomba de nível freático, independente da rede elétrica e uma pressão de saída no hidrante de mais de 4 bar;

- $\mathrm{n}_{4}=0,90$ - comprimento da conduta $>100 m$ (distância medida entre o hidrante e a entrada do edifício);

- $\mathrm{n}_{5}=0,80$ - não existe pessoal instruído.

E o índice responsável pelo aumento da segurança ao incêndio é o $n_{3}=1,00$ através da fiabilidade do sistema de abastecimento de água com reservatório elevado com reserva de água para incêndio ou bomba de nível freático, independente da rede elétrica e com uma pressão de saída no hidrante de mais de 4 bar, que vai permitir um aumento de $88,89 \%$ na segurança ao incêndio do edifício, relativamente ao valor de referência e mais baixo A1, QUADRo IV.

Para a determinação da percentagem de segurança tomou-se como combinação de referência a combinação $\mathrm{A} 1$, que tem os valores mais baixos.

No método de Gretener, quando maior é o valor obtido para a segurança ao incêndio ou seja, $\gamma \geq 1$ maior é a segurança do edifício.

A introdução de percentagens de segurança com seta apenas serve como indicativo sobre o quanto é que a segurança aumentou relativamente à combinação de referência $A 1$.
Quadro IV - Resultados das 14 Combinações.

\begin{tabular}{|c|c|c|}
\hline$\stackrel{\text { C }}{\text { Combinações }}$ & \multicolumn{2}{|c|}{$\begin{array}{c}\text { Segurança ao Incêndio } \\
Y\end{array}$} \\
\hline $\begin{array}{c}\mathrm{A} 1 \\
\text { (pior resultado) }\end{array}$ & \multicolumn{2}{|c|}{$\begin{array}{l}0,09 \\
\text { Valor de referência }\end{array}$} \\
\hline $\mathrm{A} 2$ & 0,10 & $11,11 \% \uparrow$ \\
\hline $\mathrm{A} 3$ & 0,11 & $22,22 \% \uparrow$ \\
\hline A4 & 0,10 & $11,11 \% \uparrow$ \\
\hline A5 & 0,10 & $11,11 \% \uparrow$ \\
\hline A6 & 0,11 & $22,22 \% \uparrow$ \\
\hline A7 & 0,12 & $33,33 \% \uparrow$ \\
\hline A8 & 0,13 & $44,44 \% \uparrow$ \\
\hline A9 & 0,15 & $66,67 \% \uparrow$ \\
\hline $\mathrm{A} 10$ & 0,16 & $77,78 \% \uparrow$ \\
\hline $\begin{array}{c}\mathrm{A} 11 \\
\text { (melhor resultado) }\end{array}$ & 0,17 & $88,89 \%$ 个 \\
\hline $\mathrm{A} 12$ & \multicolumn{2}{|c|}{0,09} \\
\hline $\mathrm{A} 13$ & 0,10 & $11,11 \% \uparrow$ \\
\hline A14 & 0,11 & $22,22 \% \uparrow$ \\
\hline
\end{tabular}

\section{Parâmetros adotados pelo FRAME}

$\mathrm{Na}$ análise de sensibilidade efetuada com o FRAME, tal como no método de Gretener, começou-se por fixar os valores mais baixos do fator dos recursos de água $\mathrm{W}$, do fator de proteção especial $S$, do fator de resistência ao fogo $F$, do fator de fuga $U$ e do fator de salvamento $Y$, QuAdRos V, VI, VII, VIII e IX e variou-se os valores do fator de proteção normal, QUADRo X. 
Tomou-se para a carga de incêndio mobiliária $\mathrm{Q}_{\mathrm{m}}=3750 \mathrm{MJ} / \mathrm{m}^{2}$, alto risco.

Os parâmetros $n_{1}, n_{2}, n_{3}$ e $n_{4}$ do fator de proteção normal $\mathrm{N}$, relativos a cada uma das combinações, tomam os valores indicados nas 11 combinações, de B1 a B11, do QUADRO X.

E da mesma forma que no método de Gretener resultaram 14 combinações, para o método de Frame determinaram-se 11 combinações.

QuAdro V - Fator de Recursos de água W.

\begin{tabular}{|c|c|c|}
\hline $\mathrm{w}_{1}$ & 10 & $\begin{array}{l}\text { não existe reserva de água disponível, } \\
\text { não há água armazenada }\end{array}$ \\
\hline $\mathrm{w}_{2}$ & 4 & $\begin{array}{l}\text { falta mais de } 30 \% \text { para atingir a } \\
\text { capacidade adequada no depósito }\end{array}$ \\
\hline $\mathrm{w}_{3}$ & 6 & não existe rede de distribuição \\
\hline $\mathrm{w}_{4}$ & 3 & $\begin{array}{l}\text { menos de uma ligação por cada } 100 \mathrm{~m} \\
\text { de perímetro }\end{array}$ \\
\hline$W_{5}$ & 3 & pressão estática menor que $\mathrm{H}+35 \mathrm{~m}$ \\
\hline
\end{tabular}

Fonte: Adaptado de SMET, 2008.

Quadro VI - Fator de Proteção Especial S.

\begin{tabular}{|lll|}
\hline $\mathrm{s}_{1}$ & 0 & sem deteção automática \\
\hline $\mathrm{s}_{2}$ & 0 & sem reserva de água \\
\hline $\mathrm{s}_{3}$ & 0 & $\begin{array}{l}\text { sem proteção automática do } \\
\text { compartimento }\end{array}$ \\
\hline $\mathrm{s}_{4}$ & 0 & $\begin{array}{l}\text { nenhuma corporação de bombeiros da } \\
\text { empresa }\end{array}$ \\
\hline
\end{tabular}

Fonte: Adaptado de SMET, 2008.

QuAdRo VII - Fator de Resistência ao fogo F.

\begin{tabular}{|ccc|}
\hline$f_{s}$ & 30 & $\begin{array}{r}\text { resistência ao fogo dos elementos } \\
\text { estruturais }\end{array}$ \\
\hline$f_{f}$ & 30 & resistência ao fogo das fachadas \\
\hline$f_{d}$ & 30 & resistência ao fogo dos tetos \\
\hline$f_{w}$ & 0 & $\begin{array}{c}\text { resistência ao fogo das paredes } \\
\text { interiores }\end{array}$ \\
\hline
\end{tabular}

Fonte: Adaptado de SMET, 2008.

QuAdro VIII - Fator de Fuga U.

\begin{tabular}{|lll|}
\hline$u_{1}$ & 0 & sem deteção \\
\hline$u_{2}$ & 0 & sem meios evacuação \\
\hline$u_{3}$ & 2 & sem compartimentação \\
\hline$u_{4}$ & 0 & sem proteção \\
\hline$u_{5}$ & 2 & com bombeiros voluntários \\
\hline
\end{tabular}

Fonte: Adaptado de SMET, 2008.
QuADRo IX - Fator de Salvamento Y.

\begin{tabular}{|lll|}
\hline$y_{1}$ & 2 & sem proteção física \\
\hline$y_{2}$ & 2 & $\begin{array}{c}\text { salvaguarda financeira e económica dos } \\
\text { dados }\end{array}$ \\
\hline
\end{tabular}

Assim, à primeira combinação B1 correspondem os valores mais baixos e que servem de referência para a determinação das percentagens de segurança.

A primeira combinação B1 corresponde à pior possibilidade de todas ou seja, é onde $\mathrm{n}_{1}, \mathrm{n}_{2}, \mathrm{n}_{3}, \mathrm{n}_{4}$ e $\mathrm{n}_{5}$ têm os valores mais baixos possíveis.

Nas restantes combinações os valores de $n_{1}, n_{2}, n_{3}, n_{4}$ e $n_{5}$ vão variando conforme as possibilidades existentes no método de Frame.

$\mathrm{Na}$ fig.8 encontram-se representados todos os valores do fator de proteção normal ao longo das 11 combinações.

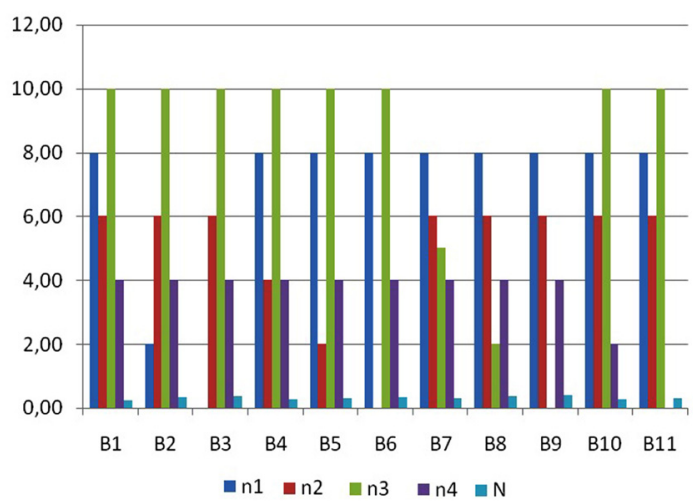

Fig. 8 - Variação do Fator de Proteção Normal N.

Os valores de W, N, S, F, U, Y, R, R1, R2 obtidos nas 11 combinações, encontram-se indicados nos gráficos da fig. 9 e fig. 10.

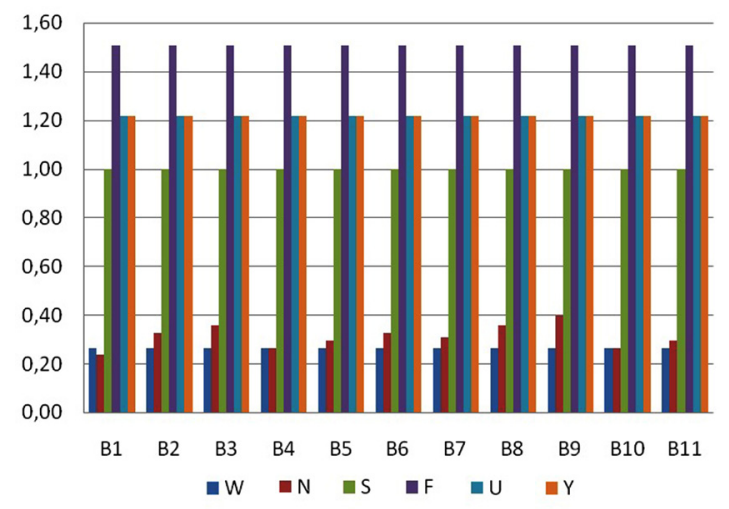

Fig. 9 - Variação das medidas W, N, S, F, U e Y. 
Quadro X - Fator de Proteção Normal N.

\begin{tabular}{|c|c|c|c|c|}
\hline $\begin{array}{c}\text { C } \\
\text { Combinações }\end{array}$ & $\begin{array}{c}\mathbf{n}_{1} \\
\text { Sistema de alarme }\end{array}$ & $\begin{array}{c}\mathbf{n}_{2} \\
\text { Meios de } 1^{\text {a } \text { intervenção }}\end{array}$ & $\begin{array}{c}\mathbf{n}_{3} \\
\text { Intervenção dos bombeiros }\end{array}$ & $\begin{array}{c}\mathbf{n}_{4} \\
\text { Formação }\end{array}$ \\
\hline B1 & 8,00 & 6,00 & 10,00 & 4,00 \\
\hline B2 & 2,00 & 6,00 & 10,00 & 4,00 \\
\hline B3 & 0,00 & 6,00 & 10,00 & 4,00 \\
\hline B4 & 8,00 & 4,00 & 10,00 & 4,00 \\
\hline B5 & 8,00 & 2,00 & 10,00 & 4,00 \\
\hline B6 & 8,00 & 0,00 & 10,00 & 4,00 \\
\hline B7 & 8,00 & 6,00 & 5,00 & 4,00 \\
\hline B8 & 8,00 & 6,00 & 2,00 & 4,00 \\
\hline B9 & 8,00 & 6,00 & 0,00 & 2,00 \\
\hline B10 & 8,00 & 6,00 & 10,00 & 0,00 \\
\hline B11 & 8,00 & 6,00 & 10,00 & \\
\hline
\end{tabular}

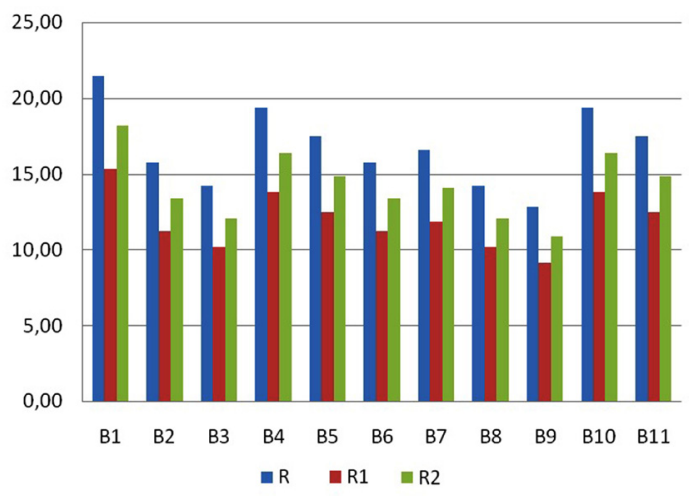

Fig. 10 - Variação dos Riscos $R, R_{1}$ e $R_{2}$.

Verifica-se que a combinação que permite obter o melhor resultado das 11 combinações no método de FRAME é a combinação $\mathrm{B} 9$, que corresponde aos valores mais baixos de $R=15,36, R_{1}=10,09$ e $R_{2}=11,99$ para o risco dos bens patrimoniais, para o risco dos ocupantes e para o risco da atividade respetivamente com um correspondente aumento da segurança ao incêndio de $40,13 \%$ para ambos os riscos.

Assim, a esta combinação B9 corresponde:

- $\mathrm{n}_{1}=8$ - sem serviço de guarda (2), sem serviço manual de alerta (2), sem garantia de notificação à brigada de incêndio (2) e sem alerta interno (2);

- $\mathrm{n}_{2}=6$ - extintores em quantidade insuficiente ou inadequados (2), não existem bocas-de-incêndio de carretel nem hidrantes interiores (4);

- $\mathrm{n}_{3}=0$ - os bombeiros chegam em menos de 10 minutos;

- $\mathrm{n}_{4}=4$ - os ocupantes não têm nenhuma formação para usar os meios de $1^{\mathrm{a}}$ intervenção.

E o parâmetro responsável pelo aumento da segurança ao incêndio é o $\mathrm{n}_{3}=0$ através da chegada dos bombeiros em menos de 10 minutos, que vai permitir um aumento de $40,13 \%$ na segurança ao incêndio para os bens patrimoniais, ocupantes e atividade tal como se pode verificar através dos resultados obtidos no QUADRO XI (BARRA et al., 2012).

Para a determinação da percentagem de segurança tomou-se como combinação de referência a combinação B1, que tem os valores mais baixos.

No método de Frame, quando maior é o valor obtido nos diferentes riscos $\mathrm{R}, \mathrm{R} 1$ e R2 $\geq 1$ pior é a segurança ao incêndio do edifício.

\section{Conclusões}

Através das combinações efetuadas com o método de Gretener e o método de FRAME é possível verificar as influências que cada um dos índices e parâmetros exercem na segurança ao incêndio das pessoas e no conteúdo e atividades existentes no interior do edifício.

Assim, para o método de Gretener, a fiabilidade do sistema de abastecimento de água tem um papel importante quando se estuda as medidas de proteção normais através das 14 combinações.

Através destas 14 combinações e tendo como ponto de referência a combinação $A 1$, que corresponde ao pior resultado, verifica-se a influência que os diversos parâmetros exercem na segurança ao incêndio do edifício.

Quanto maior é a percentagem de segurança obtida maior e melhor é a segurança ao incêndio do edifício pelo que a combinação $\mathrm{A} 11$ permite aumentar a segurança em $88,89 \%$ relativamente à combinação $\mathrm{A} 1$.

A existência de reservatórios com reserva de água e uma boa pressão de saída nos hidrantes são aspetos relevantes que não se podem deixar de ter em conta. 
QuAdRo XI - Resultados das 11 combinações.

\begin{tabular}{|c|c|c|c|}
\hline Combinações & $\begin{array}{c}\text { Risco para os Bens Patrimoniais } \\
\mathbf{R}\end{array}$ & $\begin{array}{c}\text { Risco para os Ocupantes } \\
\mathbf{R}_{\mathbf{1}}\end{array}$ & $\begin{array}{c}\text { Risco para a Atividade } \\
\mathbf{R}_{\mathbf{2}}\end{array}$ \\
\hline $\begin{array}{c}\text { B1 } \\
\text { (pior resultado) }\end{array}$ & 25,65 & 16,85 & 20,03 \\
\hline \multirow{2}{*}{ B2 } & 18,86 & 12,39 & 14,73 \\
\hline & \multicolumn{3}{|c|}{$26,49 \% \uparrow$} \\
\hline \multirow{2}{*}{ B3 } & 17,02 & 11,18 & 13,29 \\
\hline & \multicolumn{3}{|c|}{$33,66 \% \uparrow$} \\
\hline \multirow{2}{*}{ B4 } & 23,15 & 15,21 & 18,08 \\
\hline & \multicolumn{3}{|c|}{$9,75 \% \uparrow$} \\
\hline \multirow{2}{*}{ B5 } & 20,89 & 13,73 & 16,32 \\
\hline & \multicolumn{3}{|c|}{$18,55 \% \uparrow$} \\
\hline \multirow{2}{*}{ B6 } & 18,86 & 12,39 & 14,73 \\
\hline & \multicolumn{3}{|c|}{$26,49 \% \uparrow$} \\
\hline \multirow{2}{*}{ B7 } & 19,85 & 13,04 & 15,50 \\
\hline & \multicolumn{3}{|c|}{$22,62 \% \uparrow$} \\
\hline \multirow{2}{*}{ B8 } & 17,02 & 11,18 & 13,29 \\
\hline & \multicolumn{3}{|c|}{$33,66 \% \uparrow$} \\
\hline \multirow{2}{*}{$\begin{array}{c}\text { В9 } \\
\text { (melhor resultado) }\end{array}$} & 15,36 & 10,09 & 11,99 \\
\hline & \multicolumn{3}{|c|}{$40,13 \% \uparrow$} \\
\hline \multirow{2}{*}{ B10 } & 23,15 & 15,21 & 18,08 \\
\hline & \multicolumn{3}{|c|}{$9,75 \% \uparrow$} \\
\hline \multirow{2}{*}{ B11 } & 20,89 & 13,73 & 16,32 \\
\hline & \multicolumn{3}{|c|}{$18,55 \% \uparrow$} \\
\hline
\end{tabular}

No entanto, é de salientar que outros fatores como a deteção a extinção ou a intervenção do corpo de bombeiros terão de se ter em consideração, mas, neste estudo a análise de sensibilidade apenas se centrou na variação das medidas de proteção normais fixando com os valores mais baixos as medidas de proteção especial e da estrutura.

O método de FRAME é bem mais completo e permite um conhecimento mais detalhado e profundo do edifício.

Enquanto o método de Gretener apresenta os seus resultados em relação à segurança, para valores maiores que a unidade, o FRAME fá-lo relativamente ao risco mas para valores inferiores à unidade.

Através das 11 combinações efetuadas e onde se fixaram com os valores mais baixos para os fatores de recursos de água, de proteção especial, de resistência ao fogo, de fuga e de salvamento e onde se variou o fator de proteção normal obteve-se como parâmetro mais importante o tempo de chegada dos bombeiros em menos de 10 minutos.

No método de Frame quanto mais elevados são os valores dos riscos $(R, R 1, R 2 \geq 1)$ pior é a segurança ao incêndio, assim, a combinação B9 é a que obteve melhores resultados porque foi aquela onde se verificou valores mais baixos permitindo então um aumento da segurança em 40,13\% relativamente à combinação de referência $B 1$.

Através desta análise de sensibilidade efetuada com as caraterísticas apresentadas neste estudo determinou-se que a fiabilidade do sistema de abastecimento de água é o mais importante para o método de Gretener enquanto para o método de FRAME o mais importante é o tempo de intervenção dos bombeiros ou seja, quanto mais rápido os bombeiros chegarem melhor.

A escolha deste edifício foi simplesmente por se tratar de um edifício inserido na UT XII, industriais, conforme Decreto Lei 220/08 e Portaria 1532/08.

É de toda a importância efetuar-se um estudo aprofundado do edifício em análise e da atividade que nele se vai desenvolver, através de uma análise de profunda sensibilidade do método de análise de risco que se vai adotar uma vez que a situação económica atual não permite gastos desnecessários mas a segurança das pessoas deve ser sempre assegurada e nunca descurada. 
Além disso, a ponte entre o conhecimento e as experiências existentes nos diversos intervenientes de um edifício, desde o projetista até ao trabalhador fabril, é de toda a importância com vista a um aumento na contribuição para a melhoria das condições de segurança das pessoas e dos edifícios.

O crescimento tecnológico combinado com o conhecimento histórico e experiência científica permite atualmente criar mais defesas para combater e prevenir o incêndio no edifício (Fitzgerald, 2004).

\section{Referências Bibliográficas}

BarRa, C. M. P. (2010) - "Metodologia para Avaliação do Risco de Incêndio em Edifícios Industriais" - Projeto de Tese de Doutoramento, Universidade de Coimbra, Faculdade de Ciências e Tecnologia, 198 p.

Barra, C. M. P.; Rodrigues, J. P. C.; Fitzgerald, R. (2012) "Análise de Sensibilidade no Risco de Incêndio em Edifícios Industriais”, 3as Jornadas de Segurança aos Incêndios Urbanos, Universidade de Coimbra, 28 de Maio 2013, 12 p.
Decreto Lei $n^{\circ} 220 / 08$ de 12 de Novembro - Regime Jurídico da Segurança Contra Incêndio em Edifícios, Diário da República, $1^{\text {a }}$ série, 20p.

Fitzgerald, R. W. (2004) - Building Fire Performance Analysis, John Wiley e Sons Ltd, Worcester Polytechnic, Worcester, Massachusetts, USA, $515 \mathrm{p}$.

Lemos, A. M. F. T. L; Neves, I. C. N. (2004) - "Avaliação do Risco de Incêndio, Método de Cálculo" Instituto Superior Técnico, 2004, 57p.

Neves, I. C. N L; VAlente, J.C. (2004) - “Avaliação do Risco de Incêndio, Método de Cálculo” - Instituto Superior Técnico, 2004, 57p.

Portaria $n^{\circ} 1532$ / 08 de 29 de Dezembro - Regulamento Técnico de Segurança Contra Incêndio em Edifícios, Diário da República, $1^{\text {a }}$ série, $78 p$.

SMET, E. De, (2008) - "FRAME" Manual para o usuário, Offerlaan 96, B 9000 GENT Belgium, 43 p. 